\title{
A model for the identification of challenges to blended learning
}

\author{
E. A. Draffan*a and Peter Rainger ${ }^{\mathrm{b}}$ \\ ${ }^{\mathrm{a}}$ EmpTech, UK; ${ }^{\mathrm{b}}$ Key2Access Ltd, University of Sussex, UK
}

\begin{abstract}
A model for an inclusive approach to the identification of challenges to blended learning as a means to identify educational accessibility issues is presented. By focusing on both the learner and teacher perspectives, the model encompasses a broad range of factors, including learner characteristics, learning and teaching environments, interactions and activities. The proposed model provides a starting point for the identification of challenges to learning from a socio-cultural perspective rather than a medical or rehabilitation perspective. This holistic perspective is key to moving 'thinking' towards a more inclusive learning approach that embraces the needs of all learners, regardless of a defined disability.
\end{abstract}

\section{Introduction}

Blended learning has been described as learning 'that is facilitated by the effective combination of different modes of delivery, models of teaching and styles of learning, and founded on transparent communication amongst all parties involved with a course'. ${ }^{1}$ However, to ensure inclusive and accessible learning experiences that meet any challenges to the acquisition of knowledge, development of skills and experience, it is also important to take into account the full spectrum of learner characteristics. These include physical, sensory and perceptual skills, abilities, attitudes and prior knowledge.

The use of blended learning techniques takes advantage of the variety of learning experiences that can be offered by the use of a mix of learning environments (ReidYoung, 2003); for example, lectures, workshops, self-paced study, online collaboration and communication exercises, simulations and the use of interactive multimedia. In order to identify challenges to learning, it is important to investigate the components that form the learning experience and work towards the identification of issues

\footnotetext{
*Corresponding author. The Old Rectory, Rackham, Pulborough, West Sussex RH20 2EU, UK. Email: ea@emptech.info
} 
that might be causing a mismatch between the interactions used to facilitate learning and the individual characteristics and/or needs of the student.

Despite the complexity of many learning experiences, which commonly involve interactions with peers and support workers, it is felt that there are at least two perspectives within most learning situations that can be analysed to identify any challenges or barriers to learning: that of the learner and that of the teacher (educator, lecturer, tutor, etc.). We will present a model for identifying the challenges to blended learning that focuses on these two perspectives: the learner perspective and the teacher perspective.

\section{The learner perspective}

In focusing on the learner perspective learner skills (Figure 1), learner preference, content interaction and design, learning interactions and assistive technologies will be discussed.

\section{Skills}

Students' physical, sensory and perceptual skills and abilities, attitudes, coping strategies, prior knowledge and proficiency in the use of technology may all contribute

\section{Learner Characteristics}

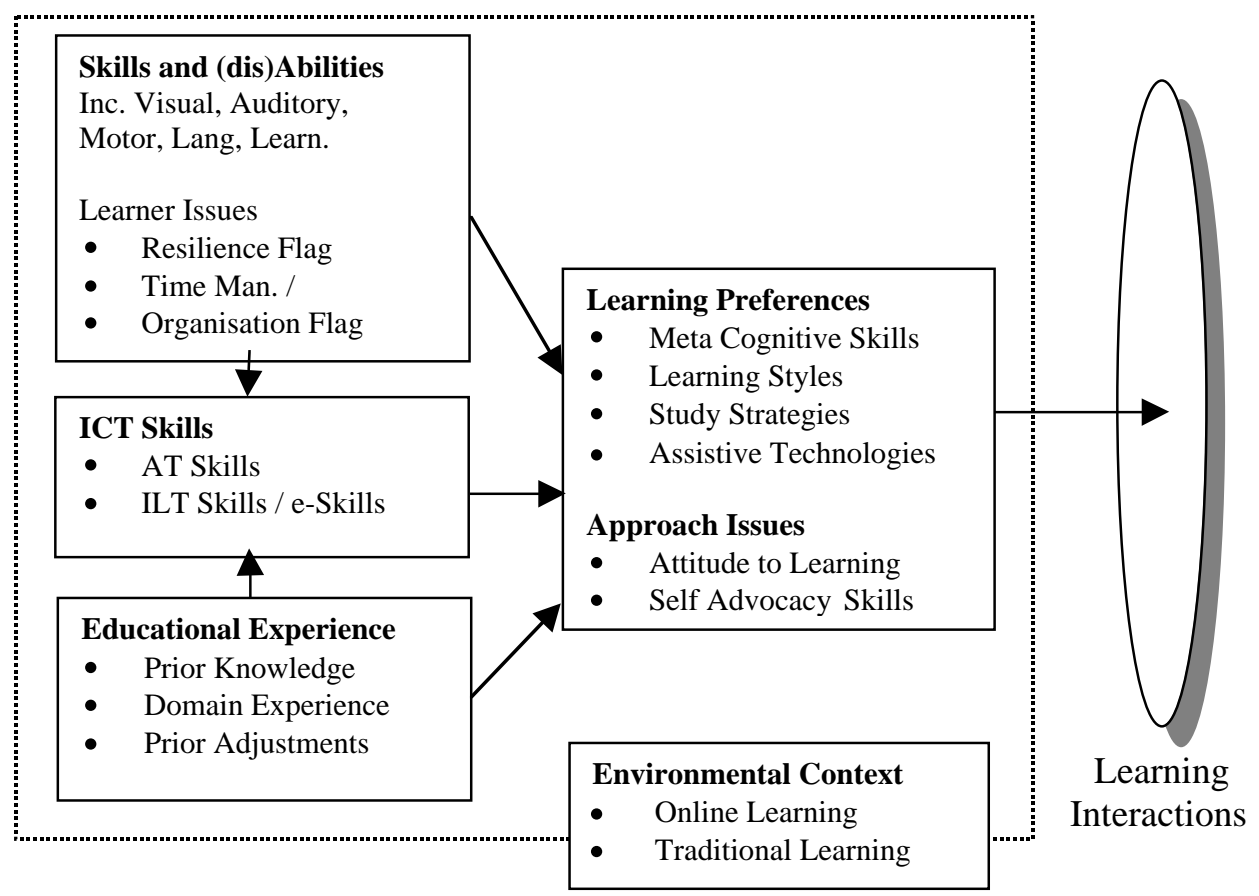

Figure 1. A model of the challenges to blended learning: from the learners' perspective 
challenges to a blended learning situation. These challenges can occur if the particular physical, sensory and perceptual skills of a student have not been taken into account when selecting the learning and teaching environment, interactions and activities. Learner skills may be described (but not limited to) using the following categories:

- Motor skills. These include the ability to control gross motor and fine motor movements along with dexterity - the coordination to make use of gross and fine motor skills; the ability to voluntarily control the body movements accurately in a situation where there are no physical difficulties; body awareness and spatial orientation; speed and accuracy of reaction to a physical stimulus.

- Visual skills. Physical and visual-motor skills include appropriate eye movements, reception of image brightness, colour, tone, texture, shape, motion, and visual acuity with issues of focus and possibly range of vision. Perception of spatial relationships is also important with visual closure, object recognition, whole/part relationships, visual (figure-ground) discrimination, depth perception and visual memory.

- Auditory skills. These skills are the sensory or physical aspects of the reception of sound within normal ranges of volume and frequency along with perceptual aspects of auditory processing. They may include phonological awareness, auditory memory, auditory sequencing, auditory blending and auditory (figureground) discrimination as well as discrimination of internal sounds.

- Language skills. These include skills of communication through written, spoken or kinaesthetic language, aspects of vocabulary range, expression, reception and comprehension skills, ability to interpret accurately semantic and syntactic ambiguities in language.

- Learning skills. Briefly, these skills may incorporate the ability to gain knowledge and understanding of both concrete and conceptual-abstract ideas, skills of reasoning, evaluation and problem-solving. Other learning skills include metacognition, self-advocacy and the re-application of concepts in differing contexts. Also, there is the ability to process information, including sequential processing, simultaneous processing and management of the flow and speed of information. There is also the ability to remember (short term and long term) or recall information even if the information is presented without a meaningful context and to hold it in the working memory alongside many other ideas.

All these skills affect or are affected by the student's resilience and coping strategies within a given environment and by the learner's preference for the use of individual skills. There may also be elements of anxiety, fatigue and pain, which impact on all aspects of learning, in addition to time management and organisational abilities.

\section{e-Skills}

A learner's proficiency for using Information Communication Technology (ICT) is as important as their attitudes, motivation and understanding of 'e-skills' or Information Learning Technology skills in any blended learning situation. The authors 
consider e-skills to be specifically related to the way students acquire and construct knowledge online while using the technologies available. There are certain issues that impact on e-skills, such as a lack of access to the appropriate technologies, awareness and expertise in the use of e-learning specific study strategies, technically inaccessible communication or collaboration services and materials that do not suit personal learning preferences. It should be noted that there may be times when the student's skills, including proficiency and competence in the use of assistive technologies, impact on the accessible nature of any learning technology used. For instance, an online discussion forum may be screen-reader friendly or accessible, but the learner may not have had the chance to acquire the skills to use the screen reader with this type of interaction in the past. It is felt that some assistive technologies are so complex that they add to the issues of anxiety and fatigue, and so on, thus affecting a student's wider abilities.

\section{Learner preferences}

Konradt et al. (2003, p. 310) mentioned the work of Rasmussen and Davidson-Shivers (1998) when they stated that 'there is also evidence that learning style dimensions can be important factors in how a given student learns more effectively' and in an ideal world there needs to be the appropriate selection and choice of a mix of delivery methods and representations of content to meet the online learners' needs. Most students have chosen methods of interacting with course materials and these preferences impact on their ability to work within an e-learning environment as much as their ability to use the technology. Gavin Reid (2001, p. 195), in his article about dyslexia, metacognition and learning styles, highlights the fact that there are more than 100 instruments designed to identify individual learning styles that do some or all of the following:

- Evaluate narrow aspects of learning such as preference for visual, auditory, tactual or kinaesthetic input.

- Focus on factors primarily associated with personality issues such as intuition, active experimentation and reflection.

- Attempt to identify how individuals process information in terms of its input, memory and expressive functions.

These instruments, however, do not always highlight the reasons why a student may have issues with various types of hypermedia and navigational elements in an e-learning situation or how they interact with the computer interface. One has to move out of the learning style arena and into the 'Human Computer Interface' world of psychology, design and information science to learn about these issues. Although there are clear cross-over points when it comes to some skills, interface design has tended to be based on the information-processing model of cognition, which establishes that (Marchionini, 1991):

- humans have a working memory limited to five to seven 'chunks' of information;

- humans must have their attention refreshed frequently; and

- recalling information requires more cognitive effort than recognising information. 
Regarding the cognitive effort required to recall or recognise information, it is much easier to use a drop-down menu that offers options rather than type in a command line without a prompt to effect an action on the computer. Touch panels may be easier to use when compared with a mouse that requires manipulation when accessing button-type options. It has been argued, therefore, that 'the design of artefacts should naturally invite task appropriate usage, where buttons have obvious uses and follow common protocols and menus are clearly marked' (Hammond, 1993, ch. 4). This also includes help files that can be designed to offer just-in-time support and contain small amounts of information rather than large chunks of inappropriate support that are not related to the problem encountered.

\section{Content interactions and design}

Discussions related to learning styles may offer concepts about how a student prefers to study while the human computer interface theories offer support for how the user interacts with the technologies. These discussions ignore, however, the issues related to the amount of content with possible information overload, lack of direction and, for some, a sense of unease about the requirements of e-learning compared with faceto-face contact.

Researchers talk about 'Field Dependence' and 'Field Independence' (Witkin et al., 1977), where those who are Field Independent tend to perform better in an exploratory situation such as that found online, and are able to restructure the knowledge they gain in a more satisfactory manner. Field Dependent learners, however, may be less able to cope with the unstructured nature of hypermedia and prefer a linear approach where there is an organised flow of work (Ford et al., 1994). This is the most efficient way of presenting information to a screen-reader user, so that they work through material in a linear structured sequence. This is not necessarily the choice that would have been preferred by the learner, who may like to have the additional depth and breadth of learning offered by hypermedia. Where choice is possible it should be encouraged, and Chen (2002) suggests that with direct guidance in the form of notes as to which might be the next best page to visit, the hiding of links to irrelevant pages and annotated links with icons and/or notes, Field Dependent students become less overwhelmed.

Other learners include those 'who actively try to understand meaning by working out relationships between concepts, relating new material to previously known information' (Boyle et al., 2003, p. 269). Some people are surface learners who focus on memory strategies to retain knowledge and only use what they immediately see to inform them in a particular situation. These strategies would indicate that it is not just the quality of the presentation of the materials that is important, but also the quantity and their layout. Researchers also talk about 'self-directed learners' (Candy, 1991) who like being in charge of their learning experience, and in many cases these students have often achieved success more easily (Boyle et al., 2003).

We define 'learner preferences' as the student's preferred approach to a particular learning interaction within the context of the learning environment. As already 
illustrated, these preferences can include study strategies, knowledge management techniques and skills in the use of technologies, which have been developed through experience in response to learning skills, abilities and styles.

\section{Learning interactions and assistive technologies}

If e-skills are lacking, the student may feel overwhelmed by the amount of information; if ICT skills are inadequate, interaction with the content may be limited; and if basic usability issues have not been addressed, equal access will be compromised. It is therefore important to identify the different types of interactive components imbedded within online learning materials and not just the relationship with the content, readability, navigation and general environment that surrounds the learning object or module. As has been said, it is beneficial to ascertain the skills required to access these interfaces as well as to accept different learning preferences and abilities so that students can be offered an interface to suit their needs, not one that causes confusion or concern. It may help to see the online environment as a collage with frames and interactive components, not just in the form of menus and buttons, but also activities within the learning object.

An example of an activity or 'interactive component' may be a 'drag and drop' routine in an online assessment situation where words are moved from one part of the screen to another using the mouse. This would be hard to achieve if the student had literacy difficulties and/or any visual or dexterity problems, or even a lack of knowledge about how to 'grab' the word and hold down the mouse button before moving it to the correct location.

Further interactions may be necessary with the introduction of additional assistive technologies (also often known as access, enabling or adaptive technologies). Most assistive technologies are categorised by disabilities and not by user skills, abilities or links to learning preferences. The authors feel that these categorisations usually fail to contain guides to the expertise required for the use of the technology. Such guides probably do not exist at the moment, because they tend to be based on personal opinions, and are similar in style to reviews produced by 'Which' magazine. It is also felt that in an educational setting there is rarely sufficient information as to how the technologies fit with the interaction types that make up a learning experience. This can lead to missed opportunities for matching learners' needs to technologies. For example, screen readers with speech synthesisers tend to appear under category headings: 'vision', 'blind' or 'visual impairment'. In other words, they are understood as technologies for people with visual needs. However, screen readers with speech synthesisers may have a role to play in helping learners with information-processing needs to read dense print on a webpage. Another example is spell-checkers, which tend to be categorised as tools for people with dyslexia or specific learning difficulties. However, spell-checkers are rarely analysed for their ability to correct 'dyslexic-type' errors.

It is essential to undertake an evaluation of how additional assistive technologies might interact with the learning environments and their components to ensure 
accessibility. It is felt that there are times when the complexities of the combined technologies could hamper the learning process. Assistive technologies have a learning curve and it is essential to ensure adequate training time is provided and that the training is provided in the context of the students' own learning and course requirements. For instance, providing magnification users with training alongside the use of the learning materials could help them learn to appreciate where the main navigational elements are to be found and how to use important keyboard shortcuts, which may prove more effective than the use of a mouse in these circumstances.

A pragmatic approach is required as it may have to be accepted that, despite the advances in ICT and human interaction; adjustments will be necessary. Salomon states that the effectiveness of a medium depends upon its match with the learner, the context, and the task:

Learning can be facilitated to the extent that the activated skills are relevant to the demands of the learning task [...] For effective instructional communication, a match needs to be established between the cognitive demands of a learning task, the skills that are required by the codes of the message, and the learner's level of mastery of these skills. (Salomon, 1977, p. 112 [reprint edition, 1994])

\section{Practical applications for the learner perspective section of the model}

The concept of learner characteristics provides a holistic overview of the learner and goes further than educationally based descriptions of a student that take a particular focus or slant. For instance, Personal Development Plans or Individual Education Plans may contain information about a learner's accessibility needs as well as ICT skills, self-management, communication, e-skills, and so on. In higher education the development of 'ePortfolio' systems also provide an opportunity to include a broader description of a learner's characteristics that could offer invaluable information for a tutor or teacher. The IMS Access-for-All metadata specification (IMS Global Learning Consortium, 2003), in particular the Accessibility Learner Information Profile (ACCLIP), offers the technical base on which to develop such a system. Our proposed model can be used to help identify potential challenges, which along with possible adjustments, can be recorded in a student's 'ePortfolio' or electronic profile.

\section{The teaching perspective}

On designing any course, the learning objectives need to be explicitly identified, whether these are the simple transference of knowledge or less tangible concepts such as the synthesis and understanding of the subject matter, the ability to demonstrate skills or building experience. Implicit learning requirements and objectives should also be identified, such as prerequisite knowledge or the development of study skills (e.g. formal academic writing competency).

If students are to learn desired outcomes in a reasonably effective manner, then the teacher's fundamental task is to get students to engage in learning activities that are likely to result in their achieving those outcomes ... It is helpful to remember that what the 
student does is actually more important in determining what is learned than what the teacher does. (Shuell, 1986, p. 429)

The set of learning objectives should then inform course developers as to the most appropriate learning design. The learning design offers a range of learning or teaching activities that could be used to facilitate the student meeting the learning objective.

\section{The issue of context}

Any model that is developed to illustrate a teacher's perspective needs to be viewed from different levels of context and the different challenges to learning. Their relationships depend on the level at which the teacher is working. For example, at the course preparation stage it is necessary to consider learner skills, which at present often include a student's impairments but not necessarily their abilities or coping strategies. It is also important to consider elements or interactions that would affect learning objectives such as distinguishing colours when a blind student is taking part in an exercise. Quality assurance, educational standards and professional or vocational requirements also need to be taken into account.

When reviewing the course at the learning activity level, specific accessibility implications of each learning and teaching activity (e.g. oral presentations and verbal instructions), educational considerations and the availability of resources or staff skills need to be taken into account. Use cases are a helpful way to capture the functional requirements of particular students such as those who have hearing difficulties and would benefit from use of a loop system. Strategies for the adaptation of courses, or activities, can be identified in anticipation of a student's enrolment.

At the delivery level, a teacher would be considering a learner's characteristics, accessibility needs, assistive technology and learning support needs. At this level it is also possible to more accurately evaluate the impact of the adjustments required to suit a learner's preferences in light of the accessibility issues.

\section{Learning design}

Course requirements can be placed outside the environmental context box at this stage, as it is important to decide upon the use of a particular learning environment with its related interactions and activities in order to fulfil the needs of a learning objective rather than making the learning objective somehow fit into pre-defined environment with a set of rigid exercises. As can be seen from Table 1, challenges to learning become apparent as the environment is analysed. By identifying possible issues posed by the components, a mismatch of educational provision and the learner's needs can be avoided.

Other components may include written instructions, note-taking, assignments, logs and reports, collaborative group work, presentations, research and reflection, online learning, ICT, field study and assessments. It is the assessments and timed examinations that tend to pose particular concerns in some learning and teaching situations. Learners are required to demonstrate their understanding of the subject matter and 


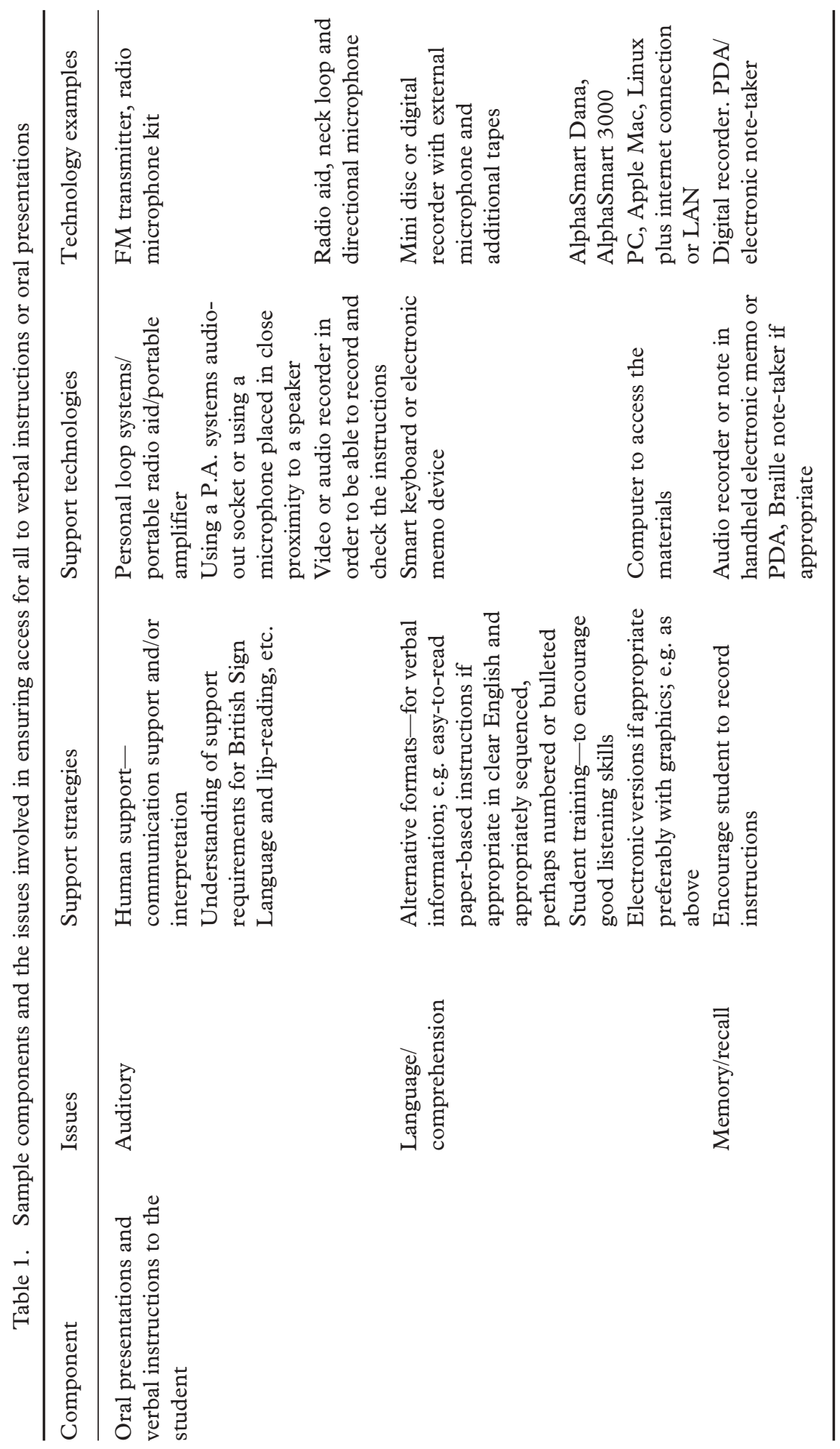


any challenges that prevent ease of access will impact on the outcome of their overall learning experience.

In cases where an accessibility issue has been found but the specific challenges to learning have not been identified, a teacher perspective model can be used to further analyse potential issues and help identify where the root of any problem is in the learning and teaching delivery provision (Figure 2). In some cases this might be traced right back to the course requirements, and questions may need to be raised as to the validity of any specific requirement that poses accessibility issues for disabled students.

\section{Practical applications for the teacher perspective section of the model}

Identifying the challenges to learning using learner characteristics, in particular skill requirements, offers the teacher the chance to evaluate the requirements for adjusting learning activities and supporting students. Within the United Kingdom, this approach has been used by the Strategies for the Creation of Inclusive Programmes of Study project, ${ }^{2}$ the Skills for Access Project ${ }^{3}$ and also within the National Federation of Access Centre Manager's Pack $^{4}$ and one of the TechDis Staff Packs. ${ }^{5}$

However, concerns remain that the present models and tools do not target e-skills and e-learning aspects of a blended learning environment with sufficient rigour. It is felt that it is important to investigate micro-scale accessibility issues from the macro perspective of the learner's overall learning experience and suggest adjustments that include practical (e.g. working in pairs) and/or pedagogic changes to the learning activity without compromising the learning experience or academic probity; for

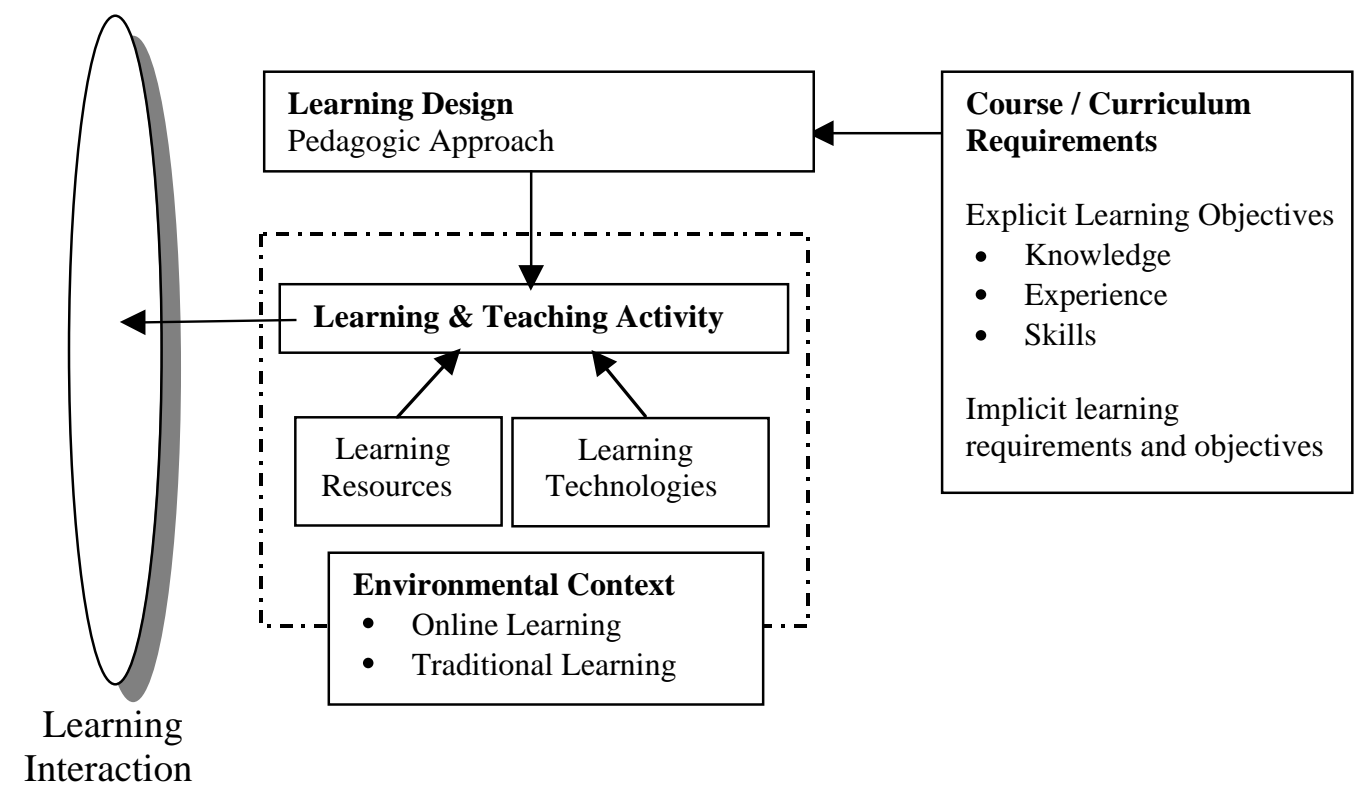

Figure 2. A model of the challenges to blended learning: from the teachers' perspective 


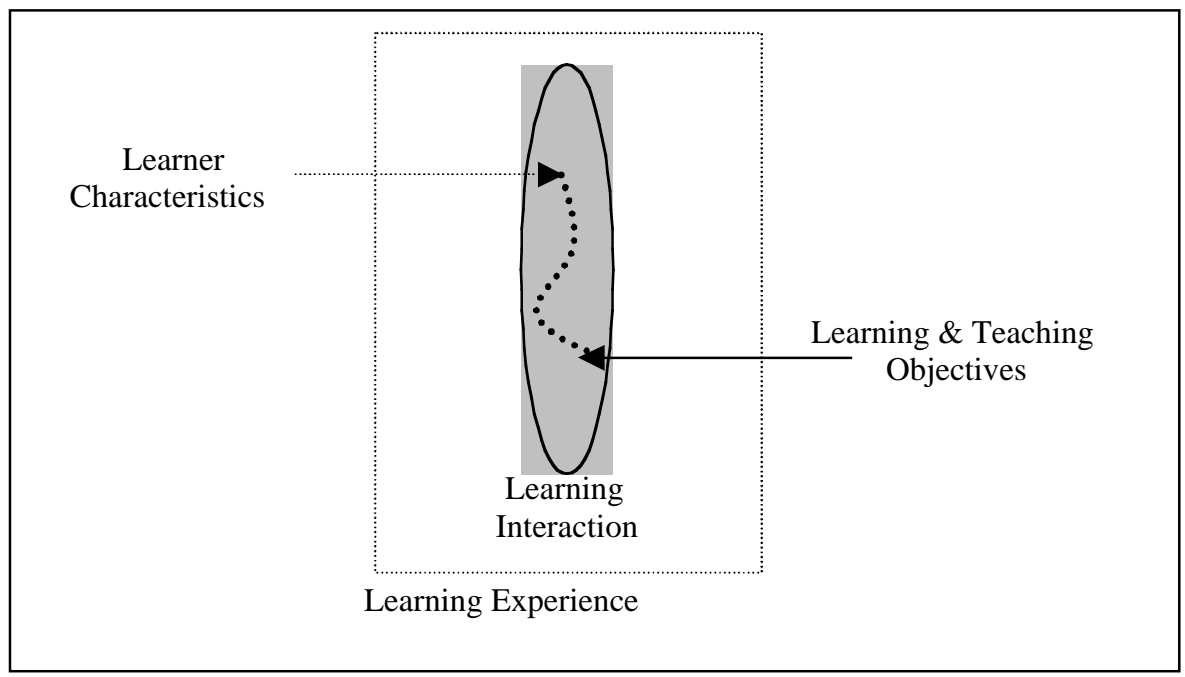

Figure 3. A model for the identification of challenges to blended learning. Note: Dotted line represents a possible challenge to learning and a path of interaction that occur.

instance, changing the interaction requirements to an appropriate alternative possibly in a different learning and teaching environment.

\section{Conclusion}

The 'Challenges to Blended Learning' model (see Figure 3) focuses on the importance of identifying challenges within learning interactions that form the students learning experience. The two perspectives (that of the learner and that of the teacher) offered cannot cover all the issues related to the interactions that occur in a blended learning situation, but it is hoped that they highlight some features that should be evaluated. It is felt that it is particularly important to acknowledge the concerns that arise with the use and proficiency of technologies in relation to learning activities, whether their use is explicit such as with 'learning technologies' (e.g. online discussion boards), assumed (e.g. MS Office Skills) or implicit such as the use of assistive technologies.

Challenges to learning can be met and overcome using a variety of approaches, but the challenges posed by a learning interaction can rarely be overcome by adjustments made on one side of the model alone. Meeting the needs of a learner's skill, abilities and preferences in order to facilitate a particular learning interaction requires the cooperation and involvement of both the educational faculty (represented by the teacher perspective) and of the student (represented by the learner perspective), along with any staff involved in their support; for example, learning support tutors (suggesting new study strategies) or assistive technologists (working on technological support).

It is also important to recognise that learning interactions are represented in the model by a plane and not by a line. The representation is used to emphasise the fact 
that learning interactions fall into a continuum and they are affected by many other factors. It clarifies the fact that when adjustments are made to a learning situation, there are many possible ways to approach the interaction but rarely is the pathway a direct one.

In our model, the role of the teacher (which might be played by a variety of staff from different departments) is to facilitate learning, through the facilitation of learning interactions. This is somewhat different from other models, such as the conversation model of Laurillard (2001), which deal primarily with the interactions between a single student and teacher. These interactions may actually be facilitated through the use of assistive technologies, involvement of a learner's peers, the assistance of learning support staff, the use of adapted learning materials or participation in an alternative but equally viable learning activity. Therefore, the teacher's perspective of the model is equally applicable at an institutional level and can be applied from a student support as well as an academic perspective.

The approach taken to accessibility, within a blended learning environment, is based on taking the focus away from disability and towards factors influencing the learners' interactions, which is similar to the methodology pioneered by Vygostsky in his approach to early years education:

Any physical handicap ... not only alters the child's relationship with the world, but above all affects his interaction with people. Any organic defect is revealed as a social abnormality in behaviour. It goes without question that blindness and deafness per se are biological factors. However, the teacher must deal not so much with these biological factors by themselves, but rather with their social consequences. When we have before us a blind boy as the object of education, then it is necessary to deal not so much with blindness by itself, as with those conflicts which arise for a blind child upon entering life.

(Vygotsky, 1983, p. 102)

Therefore, in order to facilitate inclusive learning, we need to ensure students can interact successfully with the technologies, themselves (through reflection), peers, teachers, support workers and learning materials. This means that the key issue in guaranteeing inclusive learning is the identification of any challenges to learning posed by the learning interactions.

A Vygostskian approach is common in the delivery of student support within all sectors of education but has only started to make headway in the delivery of higher education by faculty. The proposed model provides a starting point for the identification of challenges to learning from a socio-cultural perspective rather than a medical or rehabilitation perspective. This holistic perspective is key to moving 'thinking' towards a more inclusive learning approach that embraces the needs of all learners such as those for whom English is a Second or Other Language regardless of a defined disability.

\section{Notes}

1. Blended Learning Definition: http://en.wikipedia.org/wiki/Blended_learning

2. SCIPS project: http://www.scips.worc.ac.uk/ 
3. Skills for Access: http://www.skillsforaccess.org.uk

4. National Federation of Access Centres (now National Network of Assessment Centres): http:/ /www.nnac.org/

5. TechDis: http://www.techdis.ac.uk/

\section{References}

Boyle, E. A., Duffy, T. \& Dunleavy, K. (2003) Learning styles and academic outcome: the validity and utility of Vermunt's Inventory of Learning Styles in a British higher education setting, British Fournal of Educational Psychology, 73, 267-390.

Candy, P. C. (1991) Self-direction for lifelong learning (San Francisco, CA, Jossey-Bass).

Chen, S. (2002) A cognitive model for non-linear learning in hypermedia programmes, British Fournal of Educational Technology, 33(4), 449-460.

Ford, N., Wood, F. \& Walsh, C. (1994) Cognitive styles and online searching, Online and CD-ROM Review, 18(2), 79-86.

Hammond, N. (1993) Learning with hypertext; problems, principles, and prospects. Available online at: http://telecaster.lboro.ac.uk/HaPP/chapter4.html (accessed 5 January 2006).

IMS Global Learning Consortium (2003) IMS Learner Information Package (LIP) accessibility for LIP best practice and implementation guide. Available online at: http://www.imsglobal.org/accessibility/acclipv1p0/imsacclip_bestv1p0.html (accessed 5 January 2006).

Konradt, U., Filip, R. \& Hoffmann, S. (2003) Flow experience and positive affect during hypermedia learning, British fournal of Educational Technology, 34(3), 309-327.

Laurillard, D. (2001). Rethinking university teaching: a framework for the effective use of educational technology (London, Routledge).

Marchionini, G. (1991) Psychological dimensions of user-computer interfaces, Eric Digest. Available online at: http://www.ericdigests.org/1992-5/user.htm (accessed 5 January 2006).

Rasmussen, K. L. \& Davidson-Shivers, G. V. (1998) Hypermedia and learning styles: can performance be influenced?, fournal of Educational Multimedia and Hypermedia, 7, 291-308.

Reid, G. (2001) Dyslexia, metacognition and learning styles, in: G. Shiel \& U. Ni Dhalaigh (Eds) Reading matters: a fresh start (Dublin, Reading Association of Ireland), 189-201.

Reid-Young, A. (2003) The key to e-learning is b-learning, HCi fournal of Information Development. Available online at: http://www.hci.com.au/hcisite2/journal/Key\%20to $\% 20$ elearning $\% 20$ is $\%$ 20blearning.htm (accessed 11 November 2005).

Salomon, G. (1977, reprint edition, 1994) Interaction of media, cognition, and learning (NJ: LEA).

Shuell, T. J. (1986) Cognitive conceptions of learning, Review of Education Research, 56, 411-436.

Vygotsky, L. S. (1983) Sobraniye Sochinenii [Collected Works] (vol. 5) (Moscow, Pedagogika Publisher).

Witkin, H. A., Moore, C. A., Goodenough, D. R. \& Cox, P. W. (1977) Field-Dependent and Field-Independent cognitive styles and their educational research, Review of Educational Research, 47(1), 1-64. 
